\title{
Design and characteristics of new experimental chlorhexidine dental gels with anti-staining properties
}

\author{
Zbigniew Raszewski 1,2,A,B,D,F, Agnieszka Nowakowska-Toporowska ${ }^{3,, E, F, \text {, }}$ \\ Joanna Weżgowiec ${ }^{A, C, E, F}$, Danuta Nowakowska ${ }^{3}, A, C, D, F$ \\ ${ }^{1}$ Department of Dental Techniques, Higher Management School, Białystok, Poland \\ 2 SpofaDental, Kerr Company, Jičin, Czech Republic \\ ${ }^{3}$ Department of Dental Prosthetics, Wroclaw Medical University, Poland \\ ${ }^{4}$ Department of Experimental Dentistry, Wroclaw Medical University, Poland \\ A - research concept and design; B - collection and/or assembly of data; C - data analysis and interpretation; \\ $D$ - writing the article; $E$ - critical revision of the article; $F$ - final approval of the article
}

Address for correspondence

Agnieszka Nowakowska-Toporowska

E-mail:agan0125@gmail.com

Funding sources

The study was supported by the statutory funding

from Wroclaw Medical University, Poland

Conflict of interest

None declared

Received on December 13, 2017

Reviewed on January 42018

Accepted on August 9, 2018

Published online on March 18, 2019

Cite as

Raszewski Z, Nowakowska-Toporowska A, Weżgowiec J, Nowakowska D. Design and characteristics of new experimental chlorhexidine dental gels with anti-staining properties. Adv Clin Exp Med. 2019;28(7):885-890.

doi:10.17219/acem/94152

DOI

10.17219/acem/94152

\section{Copyright}

Copyright by Author(s)

This is an article distributed under the terms of the

Creative Commons Attribution Non-Commercial License

(http://creativecommons.org/licenses/by-nc-nd/4.0/)

\section{Abstract}

Background. Chlorhexidine-based products are often used in medicine and dentistry as dental hygiene and therapeutic products, especially by patients with various oral tissue diseases. However, these products have disadvantages, such as low stability, as well as discoloration of the teeth and dental reconstruction materials.

Objectives. The aim of this study was to create and evaluate experimental chlorhexidine (CHX) gels with anti-staining properties and to compare them with 3 commercially available products.

Material and methods. For this study, 4 new formulations containing 1\% CHX and different anti-staining agents were developed. The properties of these gels were compared with 3 commercial CHX-based dental products. The pH, viscosity, disintegration in water, and anti-staining properties were evaluated.

Results. The pH level of the 4 new CHX gels ranged from 5.92 to 6.33. The viscosity of the experimental gels was higher $(85.7 \div 217.7 \mathrm{~Pa} \cdot \mathrm{s})$ than the commercial ones $(11.6 \div 72.7 \mathrm{~Pa}$. $)$ ). Among the experimental formulations with $1 \%$ CHX, the formulation with 5\% polyvinylpyrrolidone (PVP) and $0.2 \%$ citric acid and the formulation with $1 \%$ citric acid were the most stable in terms of $\mathrm{pH}$ and viscosity. The disintegration times of the experimental gels were longer (50-70 min) as compared with the commercial products (approx. $20 \mathrm{~min})$. These 2 (HX gels caused less color change of glass ionomer cements in black tea solution.

Conclusions. To conclude, 2 new experimental dental gels based on 1\% CHX, one with $1 \%$ citric acid and the second with 5\% PVP and $0.2 \%$ citric acid, had the most favorable physicochemical properties. Further research is needed to evaluate their therapeutic potential in the treatment of diseases of the oral cavity.

Key words: viscosity, disintegration time, gel, chlorhexidine rinse, anti-staining properties 
Chlorhexidine (CHX) was developed in the 1940s by Imperial Chemical Industries (ICI, Macclesfield, UK) and marketed since 1954 as a general disinfectant. ${ }^{1}$ It is a bisbiguanide antiseptic, active against both Gram-positive and Gram-negative organisms, including aerobes and anaerobes, yeast and fungi. Its mechanism of action leads to the rupture of the bacterial cell wall and precipitation of the cytoplasmic contents. Higher concentrations of CHX result in better efficacy, but also increase its side effects, such as staining of the teeth and restorations. ${ }^{1-3}$ Najafi et al. reported similar effectiveness of both $0.2 \%$ and $0.12 \%$ digluconate $\mathrm{CHX}$ mouth rinses in the reduction of plaque index and gingival index. They also found that $0.2 \% \mathrm{CHX}$ was more effective in terms of the gingival bleeding index but caused much more teeth staining than $0.12 \% \mathrm{CHX} .{ }^{4}$

Chlorhexidine has superior antiplaque activity due to its ability to adsorb and bind to soft and hard tissues. When CHX is used after brushing, an interval of at least 30 min should be kept between tooth brushing and rinsing with this chemical because of possible inactivation between various positively charged dentifrice detergents and the cationic $\mathrm{CHX} .^{5-7}$ This property of $\mathrm{CHX}$ has still not been clearly verified, but it was described for the first time in the 1970s. ${ }^{5}$

Chlorhexidine salts are available in various formulations for dental applications (mouth rinses, gels and toothpastes). ${ }^{4-9}$ Some studies have reported that CHX might be also released from methacrylic resins and experimental glass ionomer cements. ${ }^{9-11}$ Mucoadhesive dosage forms, including gels and films, have been extensively developed for the treatment of oral diseases. They are frequently used in local therapy of periodontal inflammations. Although one of the limitations of gel formulations is their inability to deliver a quantified dose of the drug to the site, gels have some advantages over other formulations, such as ease of preparation and administration, relatively faster release of the incorporated drug, as well as higher biocompatibility and mucoadhesivity. ${ }^{12}$

However, an important issue is the instability of the gels. Several studies have reported on the instability of CHX gels, based on measurements of $\mathrm{pH}$ changes and viscosity over a given period of time. . $^{13,14}$

One of the disadvantages of $\mathrm{CHX}$ is staining following long-term use. It is commonly accepted that prolonged $\mathrm{CHX}$ use can change the color of the teeth and dental restorative materials (composites and cements). Different combinations have been introduced to reduce the brown pigmentation and other side effects caused by $\mathrm{CHX}$. Various products, such as peroxoborate, polyvinylpyrrolidone (PVP), sodium metabisulfite, and ascorbic acid, are added to $\mathrm{CHX} .{ }^{15-19}$ Natural teeth have been used in in vitro tests, but the color of natural dentition depends on many factors and the typical deviation is very high. ${ }^{20,21}$ To reduce the influence of individual factors, some authors have used dental restorative materials or hydroxyapatite disks for the evaluation of color change. ${ }^{22-24}$
Due to its various advantages, $\mathrm{CHX}$ is a common agent in the treatment of different oral diseases. However, there are still some unfavorable effects related to its use. The development of new formulations with improved composition could reduce the side effects of $\mathrm{CHX}$. The purpose of this study was to develop new experimental mucoadhesive gels in vitro with $1 \% \mathrm{CHX}$ and to compare them with 3 commercially available gels.

\section{Material and methods}

\section{Preparation of the experimental gels}

For this study, 4 new formulations containing 1\% CHX with different anti-staining agents were prepared. The raw materials used for the preparation of these experimental gels are summarized in Table 1. All the materials were used without undergoing any purification process. A dark glass bottle $(60 \mathrm{~mL})$ was filled with $30 \mathrm{~g}$ of distilled water, and all the ingredients were then added. Toward the end of the process, $1.5 \mathrm{~g}$ of hydroxyethyl cellulose (Natrosol 250, Ashland Specialty Chemical Co., Convington, USA) was added as a gelling agent, together with $2.5 \mathrm{~g}$ of CHX. The samples were mixed using a magnetic stirrer (Sunlab SU1200, Mannheim, Germany) until a colorless solution was obtained. After preparation, all gels were stored at room temperature $\left(23^{\circ} \mathrm{C}\right)$ in a dark place. The properties of the experimental gels were compared with 3 commercial gels: Curasept 1\%, Curasept $0.5 \%$ (both from Curaden International AG Healthcare S.p.A., Saronno VA, Kriens, Switzerland) and Dentosan 0.5\% (Recordati S.p.A, Milan, Italy) (Table 2).

Table 1. Raw materials used to prepare the gels

\begin{tabular}{|c|c|}
\hline Formulation & Composition \\
\hline \multirow{6}{*}{$\begin{array}{l}\text { Experimental gel } \\
\text { No. } 1-4\end{array}$} & CHX digluconate 1\% (Medichem, Germany) \\
\hline & hydroxyethyl cellulose Natrosol 250 (Aqualon, USA) \\
\hline & Aroma 56041 Mint (Lipo Technologies, USA) \\
\hline & sodium hydroxide (Brenntag, Germany) \\
\hline & Tween 80 (Acumedia Manufacturers, Inc., USA) \\
\hline & glycerol (Brenntag) \\
\hline \multirow{2}{*}{$\begin{array}{l}\text { Experimental gel } \\
\text { No. } 1\end{array}$} & $\begin{array}{l}\text { polyvinylpyrrolidone 5\% (Plastodone K29/32 ISP, } \\
\text { Ashland, USA) }\end{array}$ \\
\hline & citric acid monohydrate $0.2 \%$ (Brenntag) \\
\hline $\begin{array}{l}\text { Experimental gel } \\
\text { No. } 2\end{array}$ & malic acid 0.5\% (Brenntag) \\
\hline $\begin{array}{l}\text { Experimental gel } \\
\text { No. } 3\end{array}$ & citric acid monohydrate 1\% (Brenntag) \\
\hline \multirow{2}{*}{$\begin{array}{l}\text { Experimental gel } \\
\text { No. } 4\end{array}$} & $\begin{array}{l}\text { potassium oxalate monohydrate } 1 \% 60425 \\
\text { (Sigma-Aldrich, USA) }\end{array}$ \\
\hline & citric acid monohydrate $0.22 \%$ (Brenntag) \\
\hline
\end{tabular}

CHX - chlorhexidine. 
Table 2. Commercial chlorhexidine gels used in the study

\begin{tabular}{|c|c|}
\hline Formulation & Composition \\
\hline $\begin{array}{l}\text { Curasept } 1 \% \\
\text { (Curaden International AG) }\end{array}$ & $\begin{array}{l}\text { water, propylene glycol, hydroxyl ethyl cellulose, PVP/VA copolymer, PEG 40, hydrogenated castor oil, } \\
\text { CHX digluconate, sodium acetate, aroma, acetic acid, sodium metabisulfite, ascorbic acid }\end{array}$ \\
\hline $\begin{array}{l}\text { Curasept ADS } 350 \text { 0.5\% } \\
\text { (Curaden International AG) }\end{array}$ & $\begin{array}{l}\text { propylene glycol, glycerol, xylitol, hydroxyl ethyl cellulose CHX digluconate, ascorbic acid, PEG 40, } \\
\text { hydrogenated castor oil, sodium metabisulfite, aroma, methylparaben }\end{array}$ \\
\hline $\begin{array}{l}\text { Dentosan 0.5\% } \\
\text { (Recordati S.p.A) }\end{array}$ & $\begin{array}{l}\text { propylene glycol, sorbitol, hydroxyl ethyl cellulose glycerin, CHX digluconate, xylitol, PEG 40, } \\
\text { hydrogenated castor oil, menthol, aroma, methylparaben, citric acid }\end{array}$ \\
\hline
\end{tabular}

PEG - polyethylene glycol; $\mathrm{CHX}$ - chlorhexidine.

\section{Stability of the $\mathrm{pH}$ of the gels}

For the evaluation of the stability of the gels, quantification of $\mathrm{pH}$ values was chosen. The $\mathrm{pH}$ was measured initially after the preparation of the gels, and then after 1,2 and 4 months of storage at room temperature using a Voltcraft PHT-01 ATC pH meter (CEI Conrad International Ltd., Hong Kong, China).

\section{Stability of the viscosity of the gels}

Viscosity tests were performed according to the standard procedure using a Haake rheometer (Thermo Fisher Scientific, Waltham, USA). Each experimental gel $(0.5 \mathrm{~g})$ was placed on the plate of the rheometer. The upper plate of the machine was pulled down and the instrument was run at a rotary speed of $1 \mathrm{rpm}$.

\section{Gels and their disintegration in water}

The purpose of this experiment was to observe the disintegration of the experimental gels in water. For these tests, the gel dissolution protocol found in the U.S. Pharmacopeia was followed, according to the description of the "paddle over disk" method..$^{18}$ The disk assembly for holding the gels was made of acrylic resins. A distance of $2 \pm 2 \mathrm{~mm}$ was maintained between the paddle and the surface of the disk assembly. The test container was filled with distilled water and an acrylic plate covered with $1 \mathrm{~g}$ of $\mathrm{CHX}$ gel was affixed to the bottom. The temperature was maintained at $32 \pm 0.5^{\circ} \mathrm{C}$. To simulate the saliva flow inside the mouth, the paddle rotation speed was set at $300 \mathrm{rpm}$.

\section{Anti-staining properties of the gels}

To measure the anti-staining properties of the gels, 24 glass ionomer disks ( 3 for each experiment and 3 as controls) were prepared (Kavitan LC glass ionomer cement, color A3; SpofaDental AS, Jičín, Czech Republic). The diameter of each disk was $20 \mathrm{~mm}$, and the thickness was $3 \mathrm{~mm}$. The cement was prepared by mixing $1.2 \mathrm{~g}$ of powder and $0.5 \mathrm{~g}$ of liquid with a spatula to obtain the required paste consistency. The material was then placed inside a metal form and covered with polyethylene (PE) foil on both sides. The samples were cured with a Demi Ultra curing unit
(Kerr Dental, Bioggio, Switzerland) for $20 \mathrm{~s}$ for each side. After curing, the samples were removed from the metal form, and after $24 \mathrm{~h}$ of storage in a dark place, the initial color of the disks was measured using an eXact ${ }^{\mathrm{TM}}$ colorimeter (X-Rite, Grand Rapids, USA) in normal standard light to obtain values for the lightness of the color $(\mathrm{L})$, its position between red and green (a) and its position between yellow and blue (b). In the next step, the samples were covered with $\mathrm{CHX}$ gels using a plastic spatula. All the disks were then put in a black tea solution for 1 week, since CHX gel can change the color of teeth or oral mucosa in the presence of tea or coffee as a result of the Maillard reaction..$^{25}$ Lipton tea (Unilever Food Solutions, London, UK) was prepared by placing 1 tea bag in $200 \mathrm{~mL}$ of boiling water for $5 \mathrm{~min}$. The tea solution was then poured in 10 plastic cups (about $20 \mathrm{~mL}$ each). Tweezers were used to put the disks into the tea solution. Three disks without CHX gel were also immersed in the black tea solution as a control group.

After 1 week of storage at room temperature, the samples were removed from the tea solution and cleaned with a brush under a stream of water. The color was measured for the second time with the colorimeter to obtain values L1, a1 and b1. Color changes were calculated as $\Delta \mathrm{E}$, according to the equation:

$$
\Delta E=\sqrt{(L 1-L)^{2}+(a 1-a)^{2}+(b 1-b)^{2}}
$$

\section{Statistical analysis}

The results were expressed as the mean value of 3 measurements for each sample. The data was analyzed using STATISTICA v. 12 software (StatSoft Inc., Tulsa, USA). The significance of the difference between the mean values of different groups and the control group was assessed using Student's t-test, with p-values $\leq 0.05$ or $\leq 0.005$ taken as statistically significant.

\section{Results}

\section{Stability of the $\mathrm{pH}$ of the gels}

The results of the measurements of $\mathrm{pH}$ stability are presented in Fig. 1. The initial pH levels of experimental gels 3 and 4 were found to be 6.21 and 6.31, respectively, 

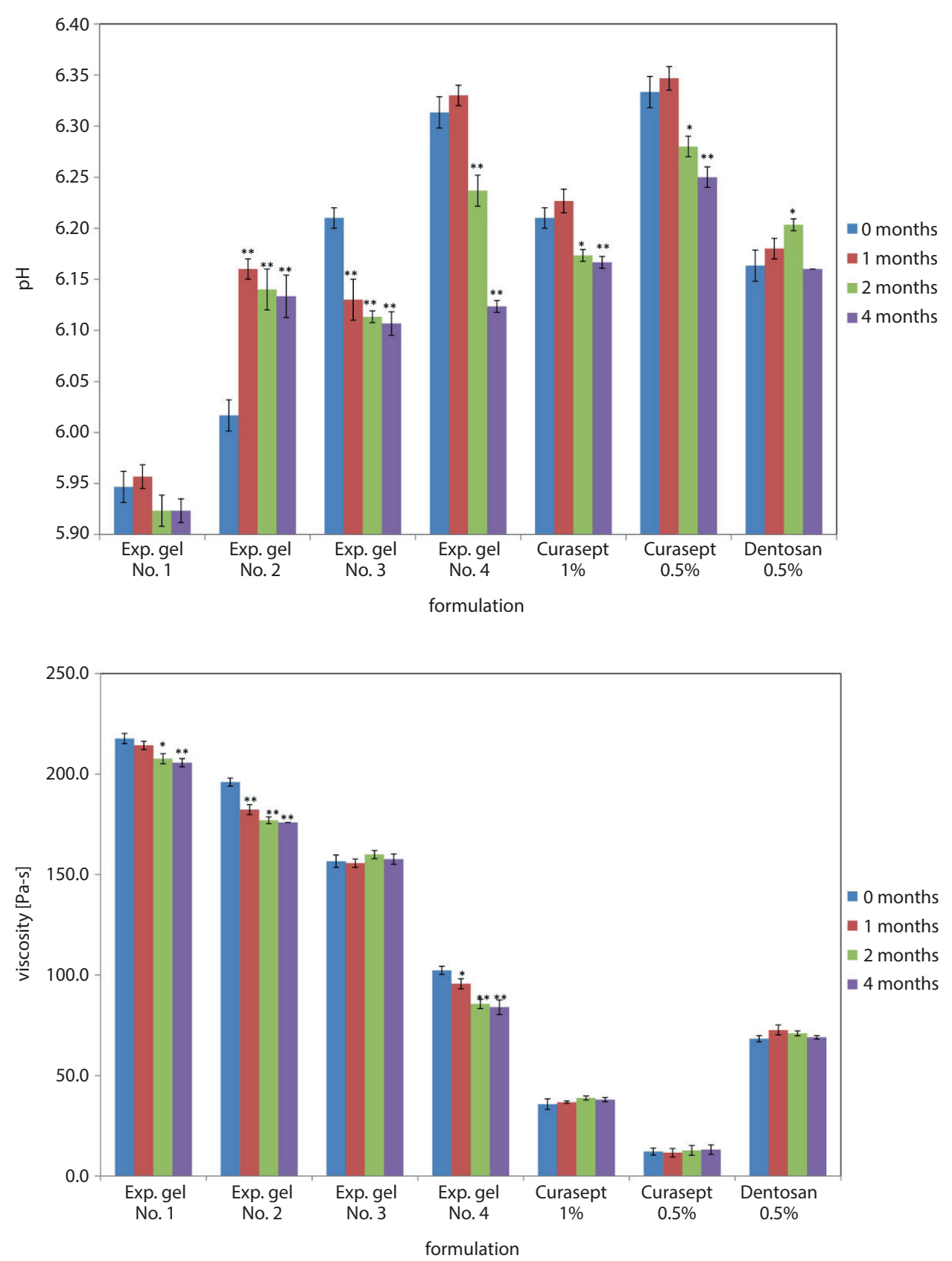

Fig. 1. The stability over time of the $\mathrm{pH}$ levels of the gels measured after the preparation of the gels and 1,2 and 4 months later; changes in $\mathrm{pH}$ level with $p$-values $\leq 0.05$ or $\leq 0.005$ were considered statistically significant
Fig. 2. The stability over time of the viscosity of the gels measured after the preparation of the gels and 1,2 and 4 months later; changes in viscosity with $p$-values $\leq 0.05$ or $\leq 0.005$ were considered statistically significant which were comparable to the initial $\mathrm{pH}$ levels of the commercial products (6.16-6.33). Experimental gels 1 and 2 had lower initial pH levels (5.95 and 6.02, respectively). After being stored for 1, 2 and 4 months, the $\mathrm{pH}$ values of both the experimental and the commercial gels changed. The maximum change in $\mathrm{pH}$ was observed in experimental gel 4 (3\% of the initial value). The most stable gel in terms of $\mathrm{pH}$ was experimental gel 1 , in which a $\mathrm{pH}$ change of only $0.4 \%$ was noted.

\section{Stability of the viscosity of the gels}

The results of measurements of the stability of the viscosity of the gels are presented in Fig. 2. Experimental gels had a higher initial viscosity (102.3-217.7 Pa.s) than the commercial products (12.2-68.3 Pa.s). Gels 1 and 3 had stable viscosity, as did the commercial products. After 2 months of storage, the viscosity of gels 2 and 4 had decreased by $10 \%$ and $16 \%$, respectively.

\section{Gels and their disintegration in water}

The results of the measurements of the disintegration time of the gels in water are summarized in Fig. 3. The commercial gels had a shorter disintegration time (19.3-22.7 $\mathrm{min}$ ) than the experimental gels used in this experiment (49.3-71.3 $\mathrm{min})$.

\section{Anti-staining properties of the gels}

Changes in the color of the glass ionomer cement after 1 week of contact with black tea solution and the $\mathrm{CHX}$ gels 


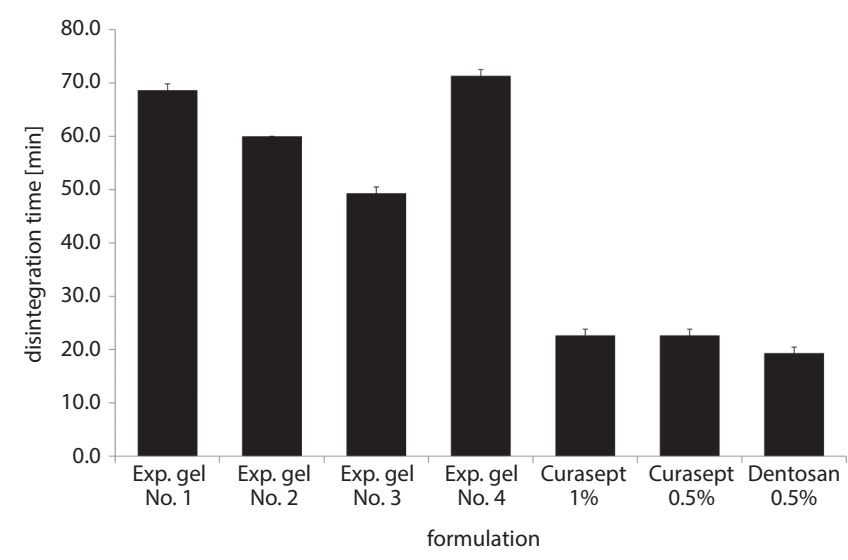

Fig. 3. Gel stability in water: a model of disintegration

are presented in Fig. 4. Black tea alone had a major influence on the color of the glass ionomer cement. In the control group, $\Delta \mathrm{E}$ was 9.2 after 1 week. In the disks that were covered with commercial gels with a lower concentration of $\mathrm{CHX}(0.5 \%)$, the color change was lower (for Curasept $0.5 \% \Delta \mathrm{E}$ was $2.9 \%$, and for Dentosan 0.5 it was $5.6 \%$ ). Treatment with Curasept with 1\% CHX resulted in the highest $\Delta \mathrm{E}$ value: $11.87 \%$. The same result was obtained for experimental gel 4. However, the disks covered with experimental gels $1-3$ showed less color change. For the experimental gel $3, \Delta \mathrm{E}$ was found to be $4.0 \%$.

\section{Discussion}

Some of the raw materials used to improve the anti-staining properties of $\mathrm{CHX}$ gels are very strong anionic substances, such as sulfide or disulfide. However, $\mathrm{CHX}$ gel is not stable in the presence of anionic substances. ${ }^{1,2,25-27}$ Aqueous solutions of $\mathrm{CHX}$ are most stable within the $\mathrm{pH}$ range from 5 to 8 . Above $\mathrm{pH} 8.0, \mathrm{CHX}$ base is precipitated and under more acidic conditions, a gradual degradation of the gel and reduction of its antibacterial activity can be observed. ${ }^{27}$
Our study revealed that after the addition of anionic substances, $\mathrm{pH}$ of the CHX gels changes over a period of time, and they start to release an unpleasant smell. For consumer acceptance, manufacturers of commercially available products containing sulfite ions need to add other substances to prevent these undesirable consequences.

In the literature, it is hypothesized that the extrinsic tooth staining associated with $\mathrm{CHX}$ and metal salts occurs due to the formation of metal sulfides. Chlorhexidine denatures proteins in the acquired pellicle by splitting disulfide bridges. This leads to the production of reactive sulfhydryl groups, which can react with iron or tin ions to produce pigmented products. ${ }^{28}$ The use of substances with reductive properties, like ascorbic or citric acids, as protection against the browning reaction was described by Ozdemir. ${ }^{25}$ Another method to obtain this effect is to use agents that can form a complex with metal ions. However, we found that during storage, not all gels incorporated with such agents are stable. For example, after 1 month of storage, gels with ascorbic acid and isoascorbic acid become yellow. Li et al. tested gels with anti-staining additives and observed that they were capable of reducing the side effect of staining of $\mathrm{CHX}$ staining. ${ }^{29}$ In our study, the best anti-staining properties (the smallest color change) were demonstrated for gels with PVP and citric acid. These compounds were able to protect glass ionomer disks from color changes resulting from a 1-week immersion in black tea solution.

The polymer used in gel preparation is an important water-soluble excipient and also serves in controlled oral drug-delivery systems. It provides thickening properties and contributes to $\mathrm{pH}$ stability, water retention and adhesion power. A similar effect of prolonged $\mathrm{CHX}$ release has also been observed in the presence of acidic polymers carrying carboxylic groups, such as polyacrylic acid or alginate. This may suggest that the formation of a complex of these substances with $\mathrm{CHX}$ may be responsible for $\mathrm{CHX}$ retention in the gel, which may be used to control its release. ${ }^{26}$ Gels made by Fini et al. with a higher concentration

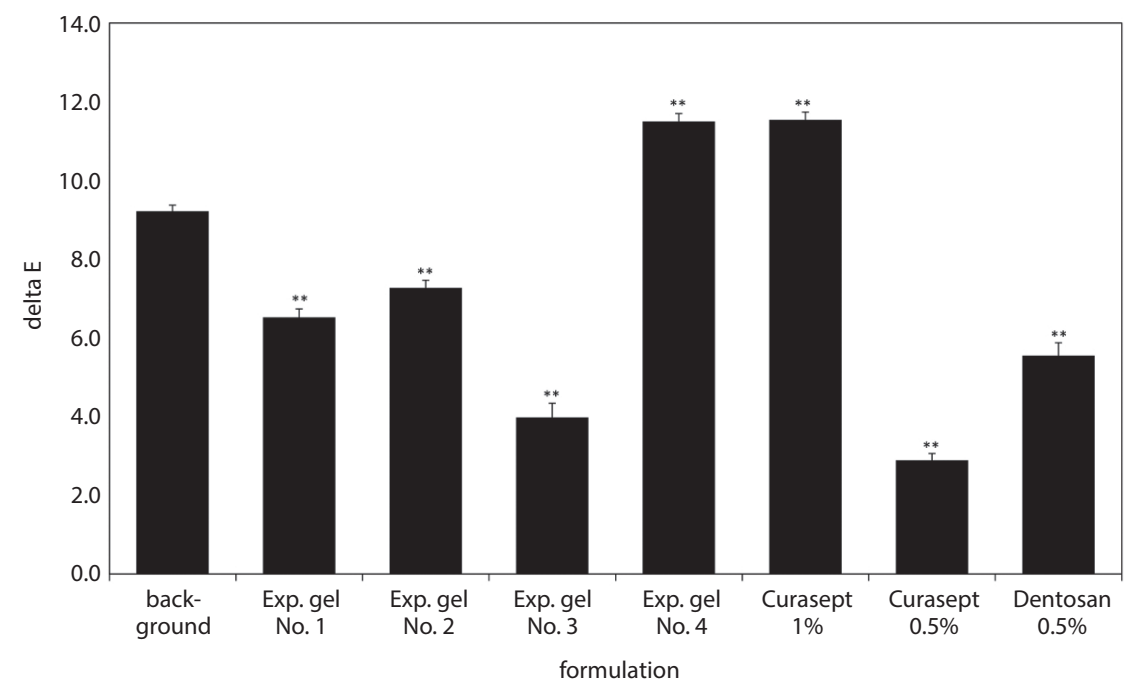

Fig. 4. Color changes in glass ionomer cement covered with CHX gels after 7 days of storage in black tea solution. Differences in the results for different gels and the controls (glass ionomer cement without gel but with black tea solution) with $p$-values $\leq 0.005$ were considered statistically significant 
of the gelling agent Lutrol (15-25\%) had a higher viscosity than commercial CHX products and other materials prepared during their study. ${ }^{26}$ For example, a gel with $25 \%$ Lutrol had a higher viscosity $(7413 \mathrm{cps}$.) than one with $20 \%$ Lutrol (827 cps.) at $37^{\circ} \mathrm{C}$.

In our study, the experimental gels had also a higher viscosity than the commercial products. The adhesion of experimental gels to the disk during the disintegration tests was better than the performance of commercial gels: disintegration times ranged between 50 and $70 \mathrm{~min}$ for the experimental gels, compared to the complete disintegration of the commercial products after approx. 20-25 min.

\section{Conclusions}

To conclude, 2 new experimental gels, based on $1 \%$ CHX, one with $1 \%$ citric acid and the other with $5 \%$ polyvinylpyrrolidone and $0.2 \%$ citric acid, showed the best physicochemical properties among the gels tested in our study. Further research is still needed to evaluate their therapeutic potential.

\section{References}

1. Eley BM. Antibacterial agents in the control of supragingival plaque: A review. Brit Dent J. 1999;186(6):286-296.

2. Mhaske MB, Nazish S, Jawade R, Bhansali A. Chemical agents in control of dental plaque in dentistry: An overview of current knowledge and future challenges. Adv Appl Sci Res. 2012;3(1):268-272.

3. Shyamacharan A, Samanth S, Varghese S. The most effective concentration of chlorhexidine as a mouthwash: Systematic review. JPSR. 2017:9(2):233-236

4. Najafi MH, Taheri M, Mokhtari MR, et al. Comparative study of $0.2 \%$ and $0.12 \%$ digluconate chlorhexidine mouth rinses on the level of dental staining and gingival indices. Dent Res J(Isfahan). 2012;9(3): 305-308.

5. Gupta R, Chandavarkar V, Galgali SR, Mishra M. Chlorhexidine: A medicine for all the oral diseases. GJMEDPH. 2012;1(2):43-48.

6. Bakaéen GS, Strahan JD. Effects of a $1 \%$ chlorhexidine gel during the healing phase after inverse bevel mucogingival flap surgery. J Clin Periodontol. 2005;7(1):20-25.

7. Slot D, Berchier C, Addy M, Van der Velden U, Van der Weijden G. The efficacy of chlorhexidine dentifrice or gel on plaque, clinical parameters of gingival inflammation and tooth discoloration: A systematic review. Int J Dent Hyg. 2014;12(1):25-35.

8. Zanatta FB, Antoniazzi RP, Rösing CK. Staining and calculus formation after $0.12 \%$ chlorhexidine rinses in plaque-free and plaque covered surfaces: A randomized trial. J Appl Oral Sci. 2010;18(5):515-520.

9. Anusavice KJ, Zhang NZ, Shen C. Controlled release of chlorhexidine from UDMA-TEGDMA resin. J Dent Res. 2006;85(10):950-954.

10. Palmer G, Jones FH, Billington RW, Pearson GJ. Chlorhexidine release from an experimental glass ionomer cement. Biomaterials. 2004; 25(23):5423-5431.
11. Patel A, Sethuraman R, Prajapati P, Patel J, Naveen YG. A comparative analysis of staining characteristics of mouthrinses on provisional acrylic resin: An in vitro study. J Interdiscip Dentistry. 2013:3:167-173.

12. Senel S, Ikinci G, Kaş S, Yousefi-Rad A, Sargon MF, Hincal AA. Chitosan films and hydrogels of chlorhexidine gluconate for oral mucosal delivery. Int J Pharm. 2000;193(2):197-203.

13. de Souza-Filho FJ, Soares A, Vianna ME, Zaia AA, Ferraz CCR. Antimicrobial effect and $\mathrm{pH}$ of chlorhexidine gel and calcium hydroxide alone and associated with other materials. Braz Dent J. 2008;19(1): 28-33.

14. Wannachaiyasit S, Phaechamud T. Development of chlorhexidine thermosensitive gels as a mouth antiseptic. JMMM. 2010;20(3):165-168.

15. Cortellini P, Labriola A, Zambelli R, Pini Prato G, Nieri M, Tonetti MS. Chlorhexidine with anti-discoloration system after periodontal flap surgery: A cross-over, randomized, triple-blind clinical trial. J Clin Periodont. 2008;35(7):641-620.

16. Derafshi R, Khorshidi H, Kalantari M, Ghaffarlou I. Effect of mouthrinses on color stability of monolithic zirconia and feldspathic ceramic: An in vitro study. BMC Oral Health. 2017;17(129):1-8.

17. Marrelli M, Amantea M, Tatullo M. A comparative, randomized, controlled study on clinical efficacy and dental staining reduction of a mouthwash containing chlorhexidine $0.20 \%$ and Anti Discoloration System (ADS). Ann Stomatol (Roma). 2015;6(2):35-42.

18. United States Pharmacopeial Convention (2011). The United States Pharmacopeia 2011: USP 35; The national formulary: NF 30. Rockville, MD: United States Pharmacopeial Convention. p. 3.

19. Lorenz K, Bruhn G, Heumann C, Netuschil L, Brecx M, Hoffmann TJ. Effect of two new chlorhexidine mouthrinses on the development of dental plaque, gingivitis, and discoloration. A randomized, investigator-blind, placebo-controlled, 3-week experimental gingivitis study. J Clin Periodontol. 2006;33(8):561-566.

20. Maanen-Schakel NW, Slot DE, Bakker EW, Van der Weijden GA. The effect of an oxygenating agent on chlorhexidine-induced extrinsic tooth staining: A systematic review. Int J Dent Hyg. 2012;10(3): 198-208.

21. Bernardi F, Pincelli MR, Carloni S, Gatto MR, Montebugnoli L. Chlorhexidine with an Anti-Discoloration System. A comparative study. Int J Dent Hyg. 2004;2(3):122-126.

22. Addy M, Moran J. Extrinsic tooth discoloration by metals and chlorhexidine. I. Surface protein denaturation or dietary precipitation? Br Dent J. 1985;159(9):281-285.

23. Menegon RF, Blau L, Janzantti NS, et al. A nonstaining and tasteless hydrophobic salt of chlorhexidine. J Pharm Sci. 2011;100(8):3130-3138.

24. Carpenter GH, Pramanik R, Proctor GB. An in vitro model of chlorhexidine-induced tooth staining. J Periodontal Res. 2005;40(3):225-230.

25. Ozdemir M. Food browning and its control [in Turkish]. Okyanus Danismanlik. 1997;1-14.

26. Fini A, Bergamante V, Ceschel GC. Mucoadhesive gels designed for the controlled release of chlorhexidine in the oral cavity. Pharmaceutics. 2011;3(4):665-680.

27. Chlorhexidine compounds in cosmetic products. Risk assessment of antimicrobial and antibiotic resistance development in microorganisms, Opinion of the Panel on Biological Hazards of the Norwegian Scientific Committee for Food Safety: VKM Report 2010:15.

28. Mathur S, Mathur T, Shrivastava R, Khatri R. Chlorhexidine: The gold standard in chemical plaque control. Nat/J Physiol Pharm Pharmacol. 2011;1(2):45-50.

29. Li W, Wang RE, Finger M, Lang NP. Evaluation of the anti-gingivitis effect of a chlorhexidine (CHX) mouthwash with or without an AntiDiscoloration System (ADS) compared to placebo during experimental gingivitis. J Investig Clin Dent. 2014;5(1):15-22. 